\title{
Motivation of Higher Education Faculty: Theoretical Approaches, Empirical Evidence, and Future Directions
}

\author{
Martin Daumiller \\ University of Augsburg
}

\author{
Robert Stupnisky \\ University of North Dakota
}

\author{
Stefan Janke \\ University of Mannheim
}

\begin{abstract}
We explore and elaborate on four questions to inspire future research on faculty motivation. The first question asks why we should be concerned with the motivations of higher education faculty in the first place, particularly in regard to studying them empirically? Moreover, if research on higher education faculty motivation is important, why is it still rather underdeveloped? Building on this, considering the plethora of motivation frameworks, we wondered which theories apply well to faculty members and how they align with one another? Finally, what should thorough international research on faculty motivation entail? This question encompasses a search for solutions on what could be done to broaden the scope of this important line research.
\end{abstract}

Keywords: faculty, university, scholar, researcher, teacher, higher education, teaching, research, tertiary, motivation, goal, expectancy, value, self-determination, intrinsic, needs, emotion, achievement

C 2020 , International Journal of Educational Research. The official citation for this manuscript is: Daumiller, M., Stupnisky,
R., \& Janke, S. (2020). Motivation of Higher Education Faculty: Theoretical Approaches, Empirical Evidence, and Future
Directions. International Journal of Educational Research, 99,101502 . doi: $10.1016 /$ j.ijer.2019.101502. This paper is not the
copy of record and may not exactly replicate the final, authoritative version of the article. The final article is available via its
DOI.

With this Special Issue, we aim to advance the (international) research on higher education faculty motivation. When reflecting on the current state of this field of research, crucial questions arose. The first question asks why we should be concerned with the motivations of higher education faculty in the first place, particularly in regard to studying them empirically? Moreover, if research on higher education faculty motivation is important, why is research on this topic still rather underdeveloped? Building on this, considering the plethora of motivation frameworks, we wondered which theories apply well to faculty members and how they align with one another? Finally, given the limited geographical distribution of this research to date, what should thorough international research on faculty motivation entail? This question encompasses a search for solutions on what could be done to broaden the scope of this research. In this introduction to the special issue, we do

\footnotetext{
Martin Daumiller, Department of Psychology, University of Augsburg; Robert Stupnisky, Education, Health \& Behavior, University of North Dakota; Stefan Janke, Department of Pedagogical Psychology, University of Mannheim.

Correspondence concerning this article should be addressed to Martin Daumiller, Department of Psychology, University of Augsburg, Universitätsstr. 10, 86159 Augsburg, Germany. Martin.Daumiller@uni-a.de. ORCID: 0000-0003-0261-6143
}

not aim to provide final answers to these questions, but rather to explore and elaborate on them to inspire future research on faculty motivation. Given the high importance of faculty motivation and the limited volume and scope of research, our objective was to bring together studies from around the world utilizing a range of established theories to understand the role of motivation in faculty success and well-being.

\section{Why should researchers study the motivations of university faculty?}

The quality of higher education (i.e., university, post secondary college) faculty performance is critical to society. Effective instruction at higher education institutions has been consistently linked to the quality of student engagement, differences in their learning outcomes, and their persistence (BrckaLorenz et al., 2012; McKeachie, 2007; Pascarella \& Terenzini, 1991, 2005; Umbach \& Wawrzynski, 2005). University faculty are also top producers of innovative research, enhance disciplinary progress, contribute to institutional visibility, and are the largest contributors to scientific progress (e.g., Javitz et al., 2010). Finally, at a societal level, faculty teaching and research can be a fundamental component of informed citizenship, scientific advancement, economic activity, and government decision- 
making (Landry et al., 2003; Perkmann et al., 2013; Weinberg et al., 2014).

Despite the importance of faculty teaching and research, there are several concerning trends regarding the cognitions and behaviors of faculty. For example, in the USA, the number of articles published in the world's major peer-reviewed journals has plateaued while research expenditures have increased, suggesting less return on investment in research (Hill et al., 2007; Javitz et al., 2010; Litwin, 2014). Relatedly, teaching is regularly de-emphasized, with even traditionally teaching-focused institutions being put under pressure to meet challenging research expectations (Eagan et al., 2014; Wilkesmann \& Schmid, 2014). This burden contributes to the high stress and burnout levels frequently reported by faculty members, e.g., in the USA (Padilla \& Thompson, 2015), Canada (Catano et al., 2010), United Kingdom (Kinman, Jones, \& Kinman, 2006), Australia (Winefeld, Boyd, Saebel, \& Pignata, 2008), and South Africa (Barkhuizen \& Rothmann, 2008).

It is a significant challenge for faculty members to perform well and make important contributions in an ever-changing working environment characterized by high teaching and research demands. Research on faculty performance to date has focused on demographic, institutional, and social-environmental factors; however, these variables have been found to explain limited variability in faculty affect and behaviors (Harrison \& Kelly, 1996; Ponjuan et al., 2011; Stupnisky et al., 2015). What has received less attention by researchers is how motivations and emotions relate to faculty experiences and behaviors such as job performance, wellbeing, and job satisfaction. The predictive utility of motivational variables on performance and well-being, over and above demographic factors, has consistently been documented among students (Lazowski \& Hulleman, 2016; Robbins et al., 2004) and K-12 teachers (Richardson et al., 2014; Tönjes \& Dickhäuser, 2009). It is reasonable that the theories and concepts of achievement motivation are just as applicable to faculty, as universities constitute achievement contexts where individual faculty are under observation to perform well in teaching and/or research.

Beyond being able to better understand and support university faculty, research on the motivations of this population can furthermore be important on a theoretical level regarding the generalizability of motivational theories (e.g., testing if constructs work in similar ways, or must be modified ), their domain specificity (aside from students, university faculty are special in that they are active in multiple, fairly equal achievement domains, see Daumiller \& Dresel, this special issue), and possible differences in the nomological net of different motivations (that can help identifying possible moderators that serve a more thorough theoretical understanding of human motivation). Research that applies concepts of achievement motivation to the work of faculty members, however, is scarce.

\section{Why has faculty motivation been studied so little?}

The amount of research on faculty motivation conducted to date is less than the amount of research in many other higher education and professional populations. Case in point, a literature search on Psycinfo on October 16, 2019 (terms searched 'intitle') yielded 2,698 publications for 'student + motivation', 758 publications for 'teacher + motivation', and 87 publications for 'faculty ${ }^{1}+$ motivation'. One may rationalize this low volume of publications by suggesting faculty constitute a small labor force and therefore may not be studied very much in general; however, a search for 'faculty + development' yielded 579 publications, indicating that there is a great deal of effort and interest invested in understanding faculty. Similar distributions are found when searching through presentations at large conferences (e.g., at the Annual Meeting of the American Educational Research Associations since 2010 there were 116 presentations on teacher motivation and 28 on faculty motivation with most of the latter directed at faculty development but not teaching or research). Finally, compared to research on school teachers, we are not aware of any meta-analyses or systematic literature reviews focused on the motivations of this particular population.

Relative to the motivation of students and K-12 teachers, one might wonder: why has the motivation of university faculty been studied so little? One explanation for this phenomenon could be grounded in the perception that faculty are highly motivated; in other words, researchers may disregard studying this population as they perceive there is no issue to resolve. Indeed, given the large investment of time required to obtain a $\mathrm{PhD}$ (and its preceding degrees), the low chances of obtaining an academic position (Woolston, 2015), and low satisfaction with salary (Cyranoski, Gilbert, Ledford, Nayar, \& Yahia, 2011), it is logical to assume that people who persevere to become faculty must be highly

\footnotetext{
${ }^{1}$ We also included other descriptors by searching for '(faculty OR university instructor OR higher education teacher OR university scholar OR researcher) AND motivation'.
} 
motivated. However, a high quantitative level of motivation does not necessarily reflect optimal motivation. Indeed, many faculty members report considerable levels of maladaptive types of motivation that implores further empirical investigation. For example, Stupnisky, BrckLorenz, and Nelson Laid (2019, this special issue) found faculty reported considerable levels of introjected and external motivation for research, which are unfavorable types of motivation according to Self-determination Theory (Deci \& Ryan, 1985, 2008). Similarly, besides favourable motivations such as strong learning goals, research also finds substantial levels of maladaptive goal pursuit in the form of performance avoidance or work avoidance goals (e.g., Daumiller et al., 2016; Daumiller et al., 2019; Daumiller \& Dresel, this special issue). Besides this, there are many possible demotivators of faculty, such as receiving rejections, unclear goals and guidelines, and committee work that is often perceived as unproductive (Minter, 2009).

A second reason for the low volume of research is that the task of researching faculty motivation can be socially intimidating and methodologically challenging. Indeed, many researchers might feel uncomfortable knocking on a colleague's office door and asking them 'how motivated are you to do your job?'. They may also consider fellow faculty too busy or stressed to participate in empirical studies (Barkhuizen \& Rothmann, 2008; Catano et al., 2010; Kinman, Jones, \& Kinman, 2006; Winefeld, Boyd, Saebel, \& Pignata, 2008). As such, researchers avoid approaching faculty members who could be unengaged or bothering colleagues to complete yet another task. Due to the scientific expertise of faculty, it may also be a concern by researchers that faculty members will critically critique their methods, or deduce their research questions and provide socially desirable responses. Despite the reality of these challenges, faculty members, as fellow researchers, know about the importance of answering truthfully and may therefore be more likely to do so. Similarly, survey response rates and quality are problematic across many populations due to factors including survey fatigue (Fan \& Yan, 2010), yet insufficient effort responding can be reduced (Huang, Curran, Keeney, Poposki, \& DeShon, 2012).

Logistics may also play a role in the low levels of research on faculty motivation. For instance, samples large and diverse enough to generate generalizability and statistical significance may be harder to obtain as university faculty make up a relatively smaller population than college students or K-12 teachers. For exam- ple, in Fall 2015 there were nearly 13 times more students and three times more K-12 teachers than full-time faculty in the United States $(19,977,270$ vs 3,633,000 vs 1,552,256; NCES, 2018; HEGIS, 2017a; HEGIS 2019), which is similar to the proportions in other countries such as Germany $(2,900,000$ vs 814,657 vs 254,967; Statistisches Bundesamt, 2019a, 2019b, 2019c). At the same time, many students are incentivized to participate in research studies (e.g., monetary incentives, course credit). Finally, many theories of motivation have not been rigorously or regularly conceptualized to faculty, nor have the respective motivation survey scales been repeatedly tested for validity and reliability. Even though it may be logistically challenging to investigate faculty motivation, it is possible given that research can rely on the same sampling techniques that have been used for other specialized groups of the labor force such as K-12 teachers. Analogously to those groups, faculty is organized within institutions (universities) and the communication channels of these organizations could be used as a contact strategy. Also, the recent increase in research on faculty motivation is leading to many theories and measures being applied to faculty (see next section), so they are being increasingly vetted for quality and may soon be more readily available.

Collectively, the potential reasons for the lack of research on faculty motivation to date leads to a clear conclusion: this is a young and developing area of research experiencing normal growing pains that can be overcome. There is no reason to regard faculty as a sacrosanct population whose motivations would not matter or not need to be addressed by motivational researchers. On the contrary, merely accepting the blind spots that exist in research on faculty motivation would likely hinder further progress in providing optimal learning contexts in higher education settings. Identifying misleading assumptions and considering solutions to important challenges that may have historically led to less research might facilitate future research on this important topic. One particularly important premise to this end, is to identify how motivation theories can be applied to faculty.

\section{What motivation theories are applicable to faculty and how do they align?}

Motivation describes the reasons why someone decides to do something, how long someone is willing to sustain an activity, and how hard he or she will pursue this activity (Dresel \& Hall, 2013; Dörnyei \& Ushioda, 2011; Gagné \& Deci, 2005; Latham \& Pinder, 2005; 
Schunk, Pintrich, \& Meece, 2008). Accordingly, motivation of university faculty can be defined as the overall processes that give rise to faculty members initiating, sustaining, and regulating goal-directed behaviors. To this end, differences in the quality of motivation (and not merely the quantity; see Pintrich, 2000a, 2000 b) can be considered meaningful to describe differences in faculty members' behaviors (e.g., how much energy they invest in preparing their classes, how many research projects they engage in), cognitions (e.g., whether they appraise help-seeking as threatening or helpful), and affects (e.g., how they experience work stressors such as teaching evaluations or manuscript rejections). The relevance of using a theoretical framework that focuses on the quality of faculty motivation has also been seen in investigations into their intrinsic motivation where investigations typically report strong levels of intrinsic motivation with only little intraindividual differences (e.g., Becker et al., 2012; Esdar et al., 2012, 2013; Wild, 2012).

In its core, an individual's current motivation is hypothesized to be composed of subjective expectations regarding the feasibility as well as the desirability of potential end states (e.g., Eccles, 1983, 2005, 2009). As such, we conceive expectancy beliefs as well as achievement goals and self-determination at the heart of ones current motivation in a specific achievement situation (see central box in Figure 1). These aspects in turn are considered to be dependent on specific, expectancy-related (e.g., self-efficacy beliefs, self-concept) and value-related (e.g., achievement goal preferences) motivational tendencies as well as more overarching personal traits (e.g., motives and needs, career choice reasons, beliefs). Both current achievement motivation and these personal tendencies are in turn considered to be partly dependent on contextual features (e.g., opportunities for self-determination, competency experiences, social interaction, goal structures), while all factors are presumed to matter for the aforementioned differences in faculty members' cognitions, behaviors, and affects (see Figure 1).

It follows that there are different theoretical-conceptual approaches to describe and understand the quantity and quality of motivation. Furthermore, depending on whether more overarching person-aspects or specific differences in a concrete achievement situation are of interest, motivation can be approached on different levels of hierarchy. Therefore, to describe and understand faculty motivation, we can derive the following central theoretical approaches that are also used in this Special Issue.
Self-efficacy beliefs (Bandura, 1977, 1997, 2001) are among the most well-researched constructs in motivation (Bong \& Clark, 1999) and were one of the first theoretical frameworks to systematically conceptualize university faculty motivation (Bailey, 1999; Forester, Kahn, \& Hesson-McInnis 2004; Hemmings and Kay 2009; Hemmings \& Kay, 2010; Morris \& Usher, 2011; Pasupathy \& Siwatu, 2014; Young \& Kline, 1996). This theoretical concept focuses on the subjective beliefs of a person regarding whether she or he believes to be able to conduct certain tasks successfully (Bandura, 1977, 1997, 2001; Klassen, Durken, \& Tze, 2014). This line of research distinguished between multiple domains that university faculty are active in, such as research, teaching, and administration/service (Major \& Dolly, 2003; Zhang, Fu, Li, \& He, 2019), in which faculty self-efficacy beliefs can be considered as separable (Ismayilova \& Klassen, this issue). While many works have been conducted regarding self-efficacy beliefs for research (e.g., Bieschke, Bishop, \& Garcia, 1996; Forester et al., 2004; O’Brien, Malone, Schmidt \& Lucas, 1998; Philips \& Russell, 1994), selfefficacy beliefs for higher education teaching are seldom independently investigated (e.g., Daumiller et al. 2016; Daumiller et al. 2019; Han et al., this special issue) but constitute a rising topic of interest. Faculty might also constitute self-efficacy as a protective factor against stress at work (e.g., Han et al., this special issue) while being a particularly valuable resource for graduate students and novice instructors (e.g., Fong et al., this special issue; Fong, Gilmore, Pinder-Grover, \& Hatcher, 2019).

In contrast to the research on self-efficacy beliefs, Achievement Goal Theory (Dweck, 1986; Elliot \& Hulleman, 2017; Nicholls, 1984) focuses more strongly on different qualities of motivations, by distinguishing different sets of goal classes that individuals can pursue to different strengths and for which different affective, cognitive, and behavioral consequences have been documented (Hulleman et al., 2010; Payne, Youngcourt, \& Beaubien, 2007). Opposed to self-efficacy beliefs, achievement goals are more strongly tied to the value aspect of motivation. The achievement goals that are pursued in a given achievement situation can be attributed to specifics of the context (e.g., emphases on different goals, e.g., Bardach et al., 2020) and to more person-stable preferences (often termed 'achievement goal orientations'). Depending on the pursued end- 


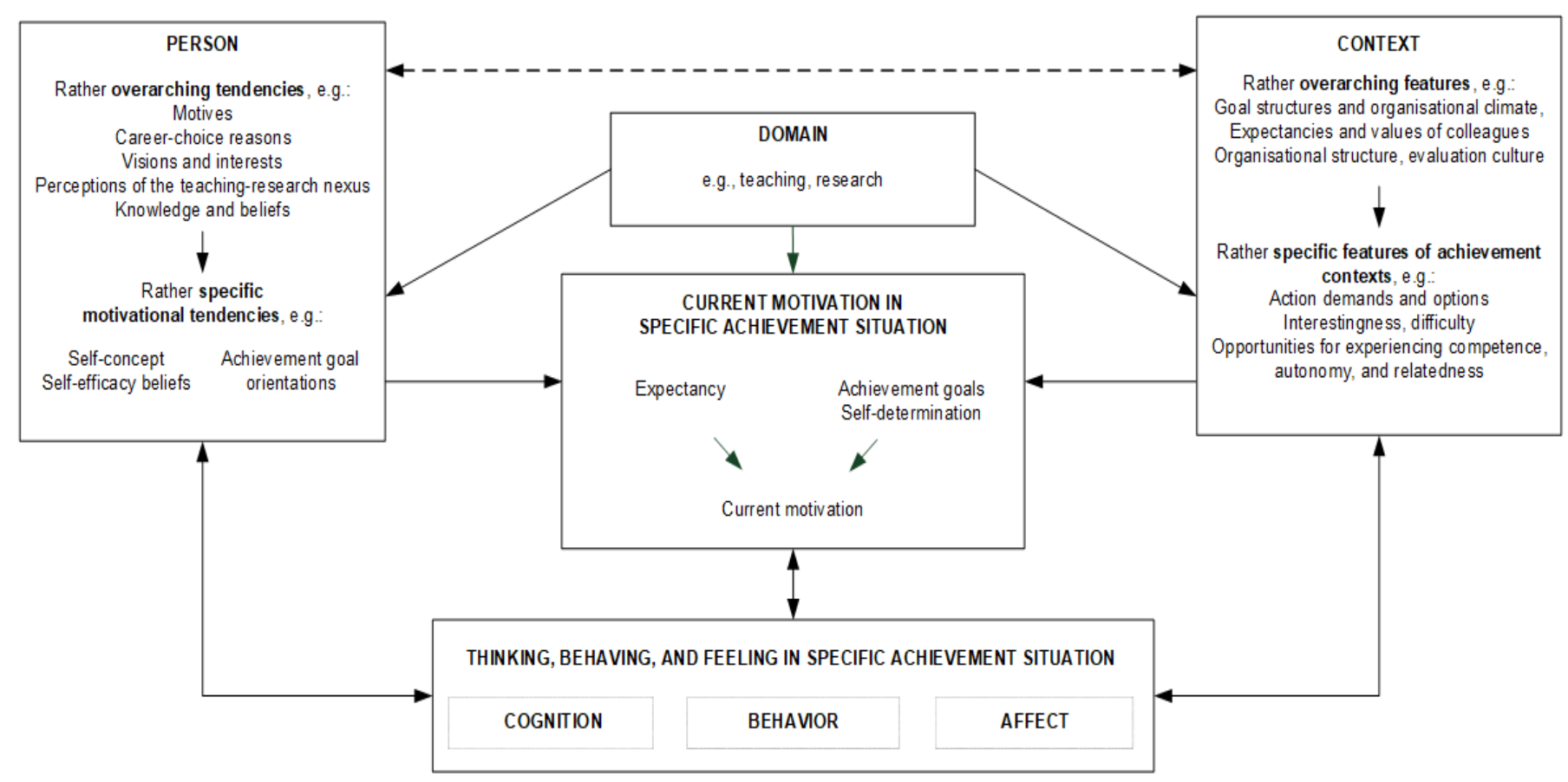

Figure 1. Conceptual overview model of faculty motivation (adapted based on Daumiller, 2019 and Dresel \& Hall, 2013)

states and the motivational systems they span up, different goals can be consolidated into different achievement goal classes. To this end, there is an ongoing debate regarding the number and content of achievement goals that should be meaningfully distinguished (e.g., Elliot \& McGregor, 2001; Elliot, Murayama, \& Pekrun, 2011; Vansteenkiste, Lens, Elliot; Soenens, \& Mouratidis, 2014). Thereby, the biggest commonality between the different conceptualizations is the differentiation between mastery-based goals (focused on how well one does on tasks and one's development of competence) and performance-based goals (focused on one's performance, relative to others and as perceived by others). Moreover, most researchers agree on the notion that goals can be characterized by an approach or avoidance goal valence (e.g., Murayama, Elliot, \& Yamagata, 2011). Building on results from interview studies documenting that scholars pursue the respective goals for teaching (Daumiller, Figas, \& Dresel, 2015) and for research (Daumiller \& Dresel, 2019b), Daumiller and colleagues (2019) have proposed an integrative achievement goal framework that is suitable to describe faculty motivation. This Hexagon model of achievement goals differentiates ten different goal classes in total and is described in greater detail in the contribution by Daumiller and Dresel within this special issue. In both the teaching and the research domain as well as across different university types and countries, pioneering research has documented the power of this model for describing university faculty members' experiences and behaviors, including student ratings of teaching behaviors, professional development, and fraudulent behaviors of faculty such as questionable research practices (Daumiller et al., 2019; Daumiller, Bieg, Dickhäuser, \& Dresel, 2019; Daumiller \& Dresel, 2019b; Daumiller et al., 2016; Daumiller, Janke, Rinas, \& Dresel, 2020; Hein, Daumiller, Janke, Dresel \& Dickhäuser, 2019, Janke \& Dickhäuser, 2018; Janke, Daumiller, \& Rudert, 2018). Finally research on this framework also investigated the separability of achievement goals for teaching and for research and their joint interplay (Daumiller \& Dresel, this special issue).

Self-determination Theory (SDT; Deci \& Ryan, $1985,2005)$ specifies a continuum of motivation types that are experienced by individuals based on the satisfaction of three basic psychological needs in a given context: autonomy, competence, and relatedness. When the three needs are supported due to what the context provides, individuals are considered likely to experience self-determined motivation in a given achievement situation. This type of motivation reflects a high valuation of the achievement task in terms of intrinsic, integrated, and identified motivations for which task engagement is deemed enjoyable and valuable. However, if the context does not allow a satisfaction of these basic needs or even thwarts them, faculty may still experience motivation but for more controlled reasons such as to avoid guilt or shame (introjected), or to 
earn rewards or avoid punishment (external). A growing number of researchers have applied SDT to faculty and found that it fits well conceptually (Deci, Kasser, \& Ryan, 1997; Lechuga \& Lechuga, 2012) and serves as a useful framework to guide empirical studies (Stupnisky et al., 2019; Stupnisky et al., 2018; Stupnisky et al., 2017). This is particularly supported by qualitative interview findings (see Guillaume \& Kalkbrenner, this special issue) as well as the applicability of this theory not only in the teaching domain but also in the research domain (see Stupnisky et al., this special issue).

Finally, another important component of motivation is the emotional experiences of individuals. In the overview model in Figure 1, emotions are a central component of how individuals feel, think, and behave in a given achievement situation which in turn is closely linked with their self-efficacy beliefs, achievement goals, and self-determination therein. Emotions include the affective, cognitive, physiological, motivational, and behavioral components that create discrete (i.e., specific) affective experiences (Kleinginna \& Kleinginna, 1981; Pekrun, 2006; Scherer, 2005). Recent studies have found that faculty experience a broad variety of emotions that can be characterized as positive/negative and activating/deactivating, ranging from enjoyment to frustration and curiosity to disappointment (Kordts-Freudinger, 2017; Stupnisky et al. 2016; Stupnisky et al. 2019). In doing so, faculty emotions have been identified as an important component for teaching (see Special Issue on Emotions in Higher Education by Bonitz, Hagenauer, Hansen, KordtsFreudinger, Mendzheritskaya, Thies, 2019). Faculty emotions have also been identified as unique across work domains, with research typically yielding more negative and teaching more positive emotions, which also correlate significantly with perceived success (Stupnisky et al. 2016; Stupnisky et al. 2019). In doing so, these studies have also found support for Pekrun's (2006) control-value theory of achievement emotions, which posits that appraisals of personal control and value are critical antecedents of achievement-related emotions and, in turn, performance (see also Thies et al., this special issue).

Taken together, the aforedescribed theories offer frameworks to understand faculty motivation and pathways to guide empirical study. The different perspectives shed light on the complex nature of motivations as well as their antecedents and effects. Given the role of different contexts and domains for these processes (see Figure 1), the comprehensive understanding of faculty motivation will profit from empirical research on faculty around the world.

\section{What would thorough international research on faculty motivation entail?}

While researchers strive to provide knowledge that is widely applicable to higher education faculty, and the aforementioned motivational frameworks are universal in nature, research on faculty motivation needs to recognize that the working environment of faculty differs heavily across countries. This is particularly the case when considering the overall model of faculty motivation that we described before. Therein, contextual aspects are considered both relevant for current motivations in a given achievement situation, more personstable motivational differences, as well as cognitions, behaviors, and affect of individuals. These contextual features can in turn be expected to differ between different countries and cultures, particularly more overarching features such as organizational climate and structure, expectations and values of colleagues, as well as evaluation culture. After all, countries differ substantially regarding faculty positions (e.g., differentiation between positions; hierarchical structure), career tracks in higher education (e.g., level of competitiveness; limitations for career pursuit bound to academic age) as well as work schedules (e.g., number of taught courses per person; diversity of work tasks), job satisfaction, and distress of faculty (Shin \& Jung, 2014).

For instance, the majority of German university faculty engage both in teaching and research tasks (Hüther \& Krücken, 2018), whereas lecturer positions characterized by an exclusive focus on teaching are rather uncommon. It makes sense that German university faculty must deal with how their teaching and research synergize (Daumiller \& Dresel, 2018; similar in the US see Stupnisky, et al., 2015) and that faculty members can experience frequent goal conflicts regarding how to distribute time between these domains (Esdar, Gorges, $\&$ Wild, 2016). Thus, the working conditions (division of time between research and teaching) shape motivational strains that may differ in their presence in different countries with different educational practices. When combining motivational research from different countries, we can provide a glimpse into the different working conditions of faculty, which can also dictate research questions within the field.

This special issue presents a first step towards a broader international understanding of faculty motivation by providing empirical findings from China (Han et al., this special issue), Germany (Daumiller \& 
Dresel, this special issue; Thies et al, this special issue.), Azerbaijan and Turkey (Ismayilova \& Klassen, this special issue), and the US (Fong et al., this special issue; Stupnisky et al., this special issue; Guillaume \& Kalkbrenner., this special issue). With the exception of the contributions by Ismayilova \& Klassen (this special issue) and Han and colleagues (this special issue), this research has been conducted primarily in the Angloamerican or German context. While research on faculty motivation is indeed an emerging research topic in Germany (e.g., Daumiller et al., 2019; Esdar et al., 2016; Hein, et al., 2019; Janke, Daumiller \& Rudert, 2019; Thies \& Kordts-Freudinger, 2019) as well as in the US (e.g., Hardré, Beesley, Miller, \& Pace, 2011; Morales, Grineski, \& Collins, 2017; Stupnisky, Hall, Daniels, \& Mensah, 2017; Stupnisky, Hall \& Pekrun, 2019; Sverdlik, Hall, Hubbard, \& McAlpine, 2018), it is important to broaden this picture. Anglo-american countries and Germany are characterized by a western educational system with highly competitive higher education job markets (Shin \& Jung, 2014). This climate may provide fertile ground for certain (normative) goals (Janke et al., 2016) and extrinsic motivation (Zhu, Gardner, \& Chen, 2018).

It is thus an ongoing endeavor to gather deeper insights into the importance of faculty motivation within non-western (such as China or Turkey; see Han et al., Ismayilova \& Klassen, this special issue) and also less competitive academic systems. One direction forward could be to encourage more scholars in diverse educational systems to conduct empirical research on faculty motivation. This approach could lead to systematic reviews and meta-analyses on the robustness of effects across different cultures. Another direction, however, would be to compare educational systems that differ in crucial variables, such as competitiveness, within cross-cultural frameworks. This approach not only allows the process to quicken by providing data on several contexts within single papers, it can also provide deep insights into the true importance of the cultural context for motivational effects. However, we have to keep in mind that cross-cultural research has to uphold to very strict methodological standards regarding standardization or control of variables; otherwise, researchers might overinterpret findings as effects of culture that are actually founded in other differences between the samples (see also Fischer \& Poortinga, 2018, regarding methodological challenges of cross-cultural research).

Even though it is difficult to provide a truly international perspective on faculty motivation, we think that this is a worthwhile endeavor. Without empirical evidence from a wide array of educational contexts, we cannot understand whether motivational effects can be generalized over cultures or how the educational context itself shapes faculty motivation and its consequences. Moreover, cross-cultural research provides the necessary variance in environmental variables that are rather homogenous within a culture (Minkov \& Hofstede, 2013). The infusion of such variation into empirical research makes it possible to get closer to a true estimate of the impact of different working environments on faculty motivation.

\section{Goals and Outline of the Special Issue}

As discussed above, there is a plethora of open questions on faculty motivation remaining that warrant rigorous research, and these research gaps are the primary inspiration for this special issue. Our elaborations on 'the why and how' of faculty motivation research have resulted in various conclusions regarding the outlook of a more systematic framework within this area of research. First and foremost, research on faculty is too important to be deterred by false assumptions or methodological challenges, which need to be recognized as common hurdles in a developing area of research that can be overcome. Second, faculty motivation should not only be defined by its quantity but also by its quality. Over the last decades, motivational research has provided very influential theoretical frameworks that explain motivation on different hierarchical levels and elaborate on how personal and contextual variables influence the quality of motivational states. While thorough testing is necessary to investigate whether and how these frameworks can be applied to faculty motivation, existing motivational theories can and should inspire the emerging field of research into faculty motivation. Third, as higher education systems differ internationally, so does the composition of faculty, their potential career tracks, and their daily working tasks. It is therefore crucial to apply an international perspective to understand what constitutes the word 'faculty' and how differences in educational systems might motivate research questions and drive effects. Finally, we believe that higher education faculty need to be investigated as a distinct population and in areas beyond their teaching. Thereby, it is important to consider all facets of faculty as this population consists of divergent groups, ranging from graduate student instructors to full professors.

The seven papers of this special issue provide examples of how the principles described above can be 
used to better understand faculty motivation. We think this collection of papers is timely as the pressure to understand faculty performance is growing and there is an urgent need for greater attention in this field. We believe this special issue should serve as a catalyst for more research on the importance and role of motivation in faculty performance. The authors provide different motivational perspectives on a diverse set of faculty groups within different contextual settings.

Fong et al. (this special issue) investigated the motivation of emerging faculty (i.e., graduate student instructors) in the US-american context. In line with social cognitive career theory (Lent, Brown, \& Hackett, 1994), they explored graduate students' self-efficacy as an important precondition for facilitating engagement in teaching at the very beginning of faculty careers.

Han et al. (this special issue) followed up on Chinese faculty members' self-efficacy beliefs and how these are associated with financial inadequacy, student quality, and perceived stress. They also explore if these associations differ between different types of institutions.

Ismayilova and Klassen (this special issue) explored self-efficacy for research and teaching, and its relationship with job satisfaction, among faculty from universities in Azerbaijan and Turkey using a mixed methods approach.

Daumiller and Dresel (this special issue) investigated the separability, associations, differences, and interplay of faculty achievement goals for teaching and research in two studies of German university scholars. Aside from discovering important groundwork for theoretical, research, and practical implications, they also investigated the congruence of goal pursuit between both domains and how this is relevant for faculty wellbeing at work.

Stupnisky et al. (this special issue) tested how factors based on SDT (Deci \& Ryan, 1985, 2008), including basic psychological needs and three motivation types, served as predictors of self-reported research productivity and number of publications among USA faculty from 19 institutions.

Guillaume and Kalkbrenner (this special issue) also utilized SDT as a framework to qualitatively explore the lived experiences of 21 Faculty of Color who successfully navigated tenure and promotion to achieve the rank of associate professor in USA departments of educational leadership and administration.

Finally, Thies et al. (this special issue) reported on an experience-sampling study in German higher education academic staff that made assessments regarding their emotions during teaching, research, and service.
The authors investigated whether faculty emotional experiences differed between these domains and how they are associated with value and control appraisals.

Above we provided only a brief description of the contributions that form this special issue on faculty motivation. The pieces are thoroughly discussed by Helen Watt and Paul Richardson (this special issue), who take a closer look at the articles and their contribution to the field. In doing so, they describe further research frontiers that have not yet been investigated and can inform future research within the emerging and promising research field of faculty motivation.

\section{References}

Austin, A. (2010). Supporting faculty members across their careers. In K. J. Gillespie \& D. L. Robertson (Eds.), A guide to faculty development (pp. 363-378). San Francisco, CA: Jossey-Brass.

Bailey, J. G. (1999). Academics' motivation and self-efficacy for teaching and research. Higher Education Research \& Development, $\quad 18, \quad 343-359$. doi:10.1080/0729436990180305

Bandura, A. (2001). Social cognitive theory: An agentic perspective. Annual Review of Psychology, 52, 1-26. doi:10.1111/1467-839X.00024

Bandura, A. (1977). Self-efficacy: Toward a unifying theory of behavioral change. Psychological Review, 84, 191215. doi:10.1037/0033-295X.84.2.191

Bandura, A. (1997). Self-efficacy: The exercise of control. New York, NY: Freeman.

Bardach, L., Oczlon, S., Pietschnig, J., \& Lüftenegger M. (2020). Has achievement goal theory been right? A metaanalysis of the relation between goal structures and personal achievement goals. Journal of Educational Psychology. Advance online publication. doi:10.1037/edu0000419

Barkhuizen, N., \& Rothmann, S. (2008). Occupational stress of academic staff in South African higher education institutions. South African Journal of Psychology, 38, 321336. doi:10.1177/008124630803800205

Becker, F. G.,Wild, E., Stegmüller, R., \& Tadsen, W. (2012). Motivation und Anreize zu ,guter Lehre“ von Neuberufenen: Schlussbericht der deutschlandweiten Befragung neuberufener Professor(inn)en im Rahmen des BMBFgeförderten MogLi Projekts. [Motivation and incentives for "good teaching" of beginners: Final report of the Germanwide survey on beginner professors in the context of the BMBF-promoted MogLi project]. Bielefeld: Universität Bielefeld.

Bieschke, K. J., Bishop, R. M., \& Garcia, V. L. (1996). The utility of the research self-efficacy scale. Journal of $\mathrm{Ca}$ reer Assessment, 4, 59-75. doi:10.1177/106907279600400104 
Bong, M., \& Clark, R. E. (1999). Comparison between selfconcept and self-efficacy in academic motivation research. Educational Psychologist, 34, 139-153. doi:10.1207/s15326985ep3403_1

Bonitz, M., Hagenauer, G., Hansen, M., Kordts-Freudinger, R., Mendzheritskaya, J., \& Thies, K. (20119). How emotions fuel teaching and learning: Multiple perspectives on emotions in higher education [Special Issue]. Studies in Higher Education, 44(10). https://www.tandfonline.com/toc/cshe20/44/10

Braithwaite, R., Spray, C. M., \& Warburton, V. E. (2011). Motivational climate interventions in physical education: A meta-analysis. Psychology of Sport and Exercise, 12, 628-638. doi:10.1016/j.psychsport.2011.06.005

BrckaLorenz, A., Ribera, T., Kinzie, J., \& Cole, E. R. (2012). Examining effective faculty practice: Teaching clarity and student engagement. To Improve The Academy, 31, 148-159. doi:10.1002/j.2334-4822.2012.tb00679.x

Catano, V., Francis, L., Haines, T., Kirpalani, H., Shannon, H., Stringer, B., \& Lozanzki, L. (2010). Occupational stress in Canadian universities: A national survey. International Journal of Stress Management, 17, 232-258. doi:10.1037/a0018582

Cyranoski, D., Gilbert, N., Ledford, H., Nayar, A., \& Yahia, M. (2011). Education: The PhD factory. Nature News, 472(7343), 276-279.

Daumiller, M. (2018). Motivation von Lehrkräften [Motivation of Teachers]. In S. Bieg \& R. Grassinger (Eds.), Enzyklopädie Erziehungswissenschaft Online [Encyclopaedia Educational Sciences Online] (pp. 1-31). Weinheim, Beltz Juventa. doi:10.3262/EEO21180403. PsyArXiv:7envh

Daumiller, M., Bieg, S., Dickhäuser, O., \& Dresel, M. (2019). Humor in university teaching: Role of teachers' achievement goals and self-efficacy for their use of content-related humor. Studies in Higher Education, 45(12), 2619-2633. https://doi.org/10.1080/03075079.2019.1623772.

Daumiller, M., Dickhäuser, O., \& Dresel, M. (2019). University instructors' achievement goals for teaching. Journal of Educational Psychology, 111, 131-148. doi:10.1037/edu0000271

Daumiller, M., \& Dresel, M. (2018). Subjective perceptions of the teaching-research nexus and occupational stress at universities. Zeitschrift für Entwicklungspsychologie und Pädagogische Psychologie, 50, 126-138. doi:10.1026/0049-8637/a000194

Daumiller, M., \& Dresel, M. (2019a). Teaching and research: Specificity and congruence of university faculty achievement goals. Advanced online publication. International Journal of Educational Research. doi:10.1016/j.ijer.2019.08.002

Daumiller, M., \& Dresel, M. (2019b). Researchers' achievement goals: Prevalence, structure, and associations with job burnout/engagement and professional learning. Con- temporary Educational Psychology, 61, 101843. Advanced online publication. https://doi.org/10.1016/j.cedpsych.2020.101843.

Daumiller, M., Figas, P., \& Dresel, M. (2015). Selbstbezogene Ziele von Dozierenden: Ergebnisse einer Interviewstudie [Achievement goals of university lecturers: Results from an interview study]. Beiträge zur Hochschulforschung/Contributions to University Research, 4, 52-64. Retrieved from http://www.bzh.bayern.de/uploads/media/4-2015-Daumiller-Figas-Dresel.pdf

Daumiller, M., Grassinger, R., Dickhäuser, O., \& Dresel, M. (2016). Structure and relationships of university instructors' achievement goals. Frontiers in Psychology, 7. doi:10.3389/fpsyg.2016.00375

Daumiller, M., Janke, S., Rinas, R., Dickhäuser, O., \& Dresel, M. (2020). Need satisfaction and achievement goals for teaching of university faculty: An international study of their interplay and relevance for positive affect, teaching quality, and professional learning. PsyArXiv:wvk2j

Deci, E. L., Kasser, T., \& Ryan, R. M. (1997). Self-determined teaching: Opportunities and obstacles. In J. L. Bess (Ed.), Teaching well and liking it: Motivating faculty to teach effectively (pp. 57-71). Baltimore, MD: The Johns Hopkins University Press.

Deci, E. L., \& Ryan, R. M. (1985). Intrinsic motivation and self-determination in human behavior. New York, NY: Plenum.

Deci, E. L., \& Ryan, R. M. (2008). Facilitating optimal motivation and psychological well-being across life's domains. Canadian Psychology/Psychologie canadienne, 49, 14-23. doi:10.1037/0708-5591.49.1.14

Dörnyei, Z., \& Ushioda, E. (2013). Teaching and researching: Motivation. New York, NY: Routledge.

Dresel, M., \& Hall, N. C. (2013). 2 Motivation. In: N. C. Hall \& T. Götz, Emotion, Motivation, and Self-Regulation: A Handbook for Teachers (pp. 57-113). Bingley, UK: Emerald.

Dweck, C. S. (1986). Motivational processes affecting learning. American Psychologist, 41, 1040-1048. doi:10.1037//0003-066x.41.10.1040

Eagan, K., Stolzenberg, E. B., Lozano, J. B., Aragon, M. C., Suchard, M. R., \& Hurtado, S. (2014). Undergraduate teaching faculty: The 2013-2014 HERI faculty survey. Los Angeles, CA: Higher Education Research Institute, UCLA.

Eccles, J. (2009). Who am I and what am I going to do with my life? Personal and collective identities as motivators of action. Educational Psychologist, 44, 78-89. doi:10.1080/00461520902832368

Eccles, J. S. (2005). Subjective task value and the Eccles et al. model of achievement-related choices. In A. J. Elliot \& C. S. Dweck (Eds.), Handbook of competence and motivation (pp. 105-121). New York, NY: The Guilford Press . 
Eccles, J. S. (1983). Expectancies, values, and academic behaviors. In J. T. Spence (Ed.), Achievement and achievement motivation (pp. 75-146). San Francisco, CA: Freeman.

Elliot, A. J., \& Hulleman, C. S. (2017). Achievement goals. In A. J. Elliot, C. S. Dweck, \& D. S. Yeager (Eds.), Handbook of competence and motivation: Theory and application, 2, (pp. 43-60). New York, NY: The Guilford Press.

Elliot, A. J., \& McGregor, H. A. (2001). A $2 \times 2$ achievement goal framework. Journal of Personality and Social Psychology, 80, 501-519. doi:10.1037/0022-3514.80.3.501

Elliot, A. J., Murayama, K., \& Pekrun, R. (2011). A $3 \times 2$ achievement goal model. Journal of Educational Psychology, 103, 632-648. doi:10.1037/a0023952

Esdar, W., Gorges, J., \& Wild, E. (2012). Karriere, Konkurrenz und Kompetenzen. Arbeitszeit und multiple Ziele des wissenschaftlichen Nachwuchses. [Career, concurrence and competences. Working time and multiple goals of young scientists.] Die Hochschule: Journal für Wissenschaft und Bildung, 21(2), 273-290.

Esdar, W., Gorges, J., \& Wild, E. (2013). Synergieeffekte und Ressourcenkonflikte von Forschung \& Lehre auf dem Weg zur Professur. [Synergetic effects and conflicts of resources of research and teaching on the way to becoming a professor.] Zeitschrift für Hochschulentwicklung, 8(3), 29-41.

Fan, W., \& Yan, Z. (2010). Factors affecting response rates of the web survey: A systematic review. Computers in Human Behavior, 26, 132-139. doi:10.1016/j.chb.2009.10.015

Fischer, R., \& Poortinga, Y. H. (2018). Addressing methodological challenges in culture-comparative research. Journal of Cross-Cultural Psychology, 49, 691-712. doi: 10.1177/0022022117738086

Fong, C. J., Gilmore, J., Pinder-Grover, T., \& Hatcher, M. (2019). Examining the impact of four teaching development programmes for engineering teaching assistants. Journal of Further and Higher Education, 43, 363-380. doi:10.1080/0309877X.2017.1361517

Fong, C. J., Jendayi, B. D., \& Hatcher, M. (2019). Teaching self-efficacy of graduate student instructors: Exploring faculty motivation, perceptions of autonomy support, and undergraduate student engagement. International Journal of Educational Research, 98. Advanced online publication. doi:10.1016/j.ijer.2019.08.018

Forester, M., Kahn, J. H., \& Hesson-McInnis, M. S. (2004). Factor structures of three measures of research self-efficacy. Journal of Career Assessment, 12, 3-16. doi:10.1177/1069072703257719

Gagné, M., \& Deci, E. L. (2005). Self-determination theory and work motivation. Journal of Organizational Behavior, 26, 331-362. doi:10.1002/job.322

Guillaume, R. O., \& Kalkbrenner, M. T. (2019). The utility of self-determination theory in faculty of color's successful pursuit of tenure and promotion to the rank of associ- ate professor. International Journal of Educational Research, 98. Advanced online publication. doi:10.1016/j.ijer.2019.09.007

Hardré, P. L., Beesley, A. D., Miller, R. L., \& Pace, T. M. (2011). Faculty motivation to do research: Across disciplines in research-extensive universities. Journal of the Professoriate, 5(1), 35-69.

Harrison, A. L., \& Kelly, D. G. (1996). Career satisfaction of physical therapy faculty during their pretenure years. Physical Therapy, 76, 1202-1218. doi:10.1093/ptj/76.11.1202

Hein, J., Daumiller, M., Janke, S., Dresel, M., \& Dickhäuser, O. (2019). How learning time mediates the impact of university scholars' learning goals on professional learning in research and teaching. Learning and Individual Differences, 72, 15-25. doi:10.1016/j.lindif.2019.04.002.

Hemmings, B., \& Kay, R. (2010). Research self-efficacy, publication output, and early career development. International Journal of Educational Management, 24, 562574. doi:10.1108/09513541011079978

Hemmings, B., \& Kay, R. (2009). Lecturer self efficacy: Its related dimensions and the influence of gender and qualifications. Issues in Educational Research, 19(3), 243254.

Hill, D., Rapoport, A., Lehming, R. F., \& Bell, R. (2007). Changing US output of scientific articles: 1988-2003. NSF-07-320. Arlington, VA: NSF.

Huang, J. L., Curran, P. G., Keeney, J., Poposki, E. M., \& DeShon, R. P. (2012). Detecting and deterring insufficient effort responding to surveys. Journal of Business and Psychology, 27, 99-114. doi:10.1007/s10869-0119231-8

Hüther, O., \& Krücken, G. (2018). Higher education in Germany: Recent developments in an international perspective (Vol. 49). Berlin: Springer.

Hulleman, C. S., Godes, O., Hendricks, B. L., \& Harackiewicz, J. M. (2010). Enhancing interest and performance with a utility value intervention. Journal of Educational Psychology, 102, 880-895. doi:10.1037/a0019506

Ismayilova, K., \& Klassen, R. M. (2019). Research and teaching self-efficacy of university faculty: Relations with job satisfaction. International Journal of Educational Research, 98. Advanced online publication. doi:10.1016/j.ijer.2019.08.012

Janke, S., Daumiller, M., \& Rudert, S. C. (2019). Dark pathways to achievement in science: Researchers' achievement goals predict engagement in questionable research practices. Social Psychological and Personality Science, 10, 783-791. doi:10.1177/1948550618790227

Janke, S., \& Dickhäuser, O. (2018). A situated process model of vocational achievement goal striving within members of the academic staff at university. Motivation and Emotion, 42. 466-481. doi:10.1007/s11031-017-9657-z

Janke, S., Nitsche, S., Praetorius, A. K., Benning, K., Fasching, M., Dresel, M., \& Dickhäuser, O. (2016). Deconstructing performance goal orientations: The merit of a 


\section{DAUMILLER ET AL.}

dimensional approach. Learning and Individual Differences, 50, 133-146. doi:10.1016/j.lindif.2016.08.013

Javitz, H., Grimes, T., Hill, D., Rapoport, A., Bell, R., Fecso, R., \& Lehming, R. (2010). U.S. academic scientific publishing. Working paper SRS 11-201. Arlington, VA: National Science Foundation, Division of Science Resources Statistics.

Kinman, G., Jones, F., \& Kinman, R. (2006). The well-being of the UK academy, 1998-2004. Quality in Higher Education, 12, 15-27. doi:10.1080/13538320600685081

Klassen, R., Durksen, T., \& Tze, V. (2014). Teachers' selfefficacy beliefs. In P. W. Richardson, S. A. Karabenick, \& H. M. G. Watt (Eds.), Teacher Motivation (pp. 100150). New York, NY: Routledge.

Kordts-Freudinger, R., Große Honebrink, T., \& Festner, D. (2017). Tiefenlernen im Praxissemester: Zusammenhänge mit Emotionsregulation. [Deep learning in practical semester: Connections with emotion regulation.] Zeitschrift für Hochschulentwicklung, 12(1), 175-194.

Kleinginna, P. R., \& Kleinginna, A. M. (1981). A categorized list of emotion definitions, with suggestions for a consensual definition. Motivation and Emotion, 5, 345379. doi:10.1007/BF00992553

Landry, R., Lamari, M., \& Amara, N. (2003). The extent and determinants of the utilization of university research in government agencies. Public Administration Review, 63, 192-205. doi:10.1111/1540-6210.00279

Latham, G. P., \& Pinder, C. C. (2005). Work motivation theory and research at the dawn of the twenty-first century. Annual Review of Psychology, 56, 485-516. doi:10.1146/annurev.psych.55.090902.142105

Lazowski, R. A., \& Hulleman, C. S. (2016). Motivation interventions in education: A meta-analytic review. Review of Educational Research, 86, 602-640. doi:10.3102/0034654315617832

Lechuga, V. M., \& Lechuga, D. C. (2012). Faculty motivation and scholarly work: Self-determination and self-regulation perspectives. Journal of the Professoriate, 6(2), 95-97.

Lent, R. W., Brown, S. D., \& Hackett, G. (1994). Toward a unifying social cognitive theory of career and academic interest, choice, and performance. Journal of Vocational Behavior, 45, 79-122. doi:10.1006/jvbe.1994.1027

Litwin, J. (2014). Who's getting the biggest research bang for the buck. Studies in Higher Education, 39, 771-785. doi:10.1080/03075079.2012.754860

Major, C., \& Dolly, J. (2003). The importance of graduate program experiences to faculty self-efficacy for academic tasks. The Journal of Faculty Development, 19(2), 89-100.

McKeachie, W. J. (2007). Good teaching makes a difference-And we know what it is. In R. P. Perry \& J. C. Smart (Eds.), The scholarship of teaching and learning in higher education: An evidence-based perspective (pp. 457-474). Dordrecht: Springer.
Minkov, M., \& Hofstede, G. (2013). Cross-cultural analysis: The science and art of comparing the world's modern societies and their cultures. Los Angeles, CA: Sage.

Minter, R. L. (2009). The paradox of faculty development. Contemporary Issues in Education Research (CIER), 2, 65-70. doi:10.19030/cier.v2i4.1073

Morales, D. X., Grineski, S. E., \& Collins, T. W. (2017). Faculty motivation to mentor students through undergraduate research programs: A study of enabling and constraining factors. Research in Higher Education, 58, 520-544. doi:10.1007/s11162-016-9435-x

Morris, D., \& Usher, E. L. (2011). Developing teaching selfefficacy in research institutions: A study of award-winning professors. Contemporary Educational Psychology, 36, 232-245. doi:10.1016/j.cedpsych.2010.10.005

Murayama, K., Elliot, A. J., \& Yamagata, S. (2011). Separation of performance-approach and performance-avoidance achievement goals: A broader analysis. Journal of Educational Psychology, 103, 238-256. doi:10.1037/a0021948

Nicholls, J. G. (1984). Conceptions of ability and achievement motivation. In R. Ames \& C. Ames (Eds.), Research on motivation in education (Vol. 1, pp. 39-73). San Diego, CA: Academic Press.

O'Brien, K. M., Malone, M. E., Schmidt, C. K., \& Lucas, M. S. (1998). Research self-efficacy: Improvements in instrumentation. Paper presented in the American Psychological Association Conference, San Francisco, CA.

Padilla, M. A., \& Thompson, J. N. (2016). Burning out faculty at doctoral research universities. Stress and Health, 32, 551-558. doi:10.1002/smi.2661

Pasupathy, R., \& Siwatu, K. O. (2014). An investigation of research self-efficacy beliefs and research productivity among faculty members at an emerging research university in the USA. Higher Education Research \& Development, 33, 728-741. doi:10.1080/07294360.2013.863843

Pascarella, E. T., \& Terenzini, P. T. (1991). How college affects students: Findings and insights from twenty years of research. San Francisco, CA: Jossey-Bass Inc.

Pascarella, E. T., \& Terenzini, P. T. (2005). How College Affects Students: A Third Decade of Research. Volume 2. Indianapolis, IN: Jossey-Bass Inc.

Payne, S. C., Youngcourt, S. S., \& Beaubien, J. M. (2007). A meta-analytic examination of the goal orientation nomological net. Journal of Applied Psychology, 92, 128150. doi:10.1037/0021-9010.92.1.128

Pekrun, R. (2006). The control-value theory of achievement emotions: Assumptions, corollaries, and implications for educational research and practice. Educational Psychology Review, 18, 315-341. doi:10.1007/s10648-0069029-9

Perkmann, M., Tartari, V., McKelvey, M., Autio, E., Broström, A., D'Este, P., ... \& Krabel, S. (2013). Academic engagement and commercialisation: A review of the literature on university-industry relations. Research Policy, 42, 423-442. doi:10.1016/j.respol.2012.09.007 
Philips, J. C., \& Russell, R. K. (1994). Research Self-Efficacy, the research training environment, and research productivity among graduate students in counseling psychology. The Counseling Psychology, 22, 628-641. doi:10.1177/0011000094224008

Pintrich, P. R. (2000a). An achievement goal theory perspective on issues in motivation terminology, theory, and research. Contemporary Educational Psychology, 25, 92 104. doi:10.1006/ceps.1999.1017

Pintrich, P. R. (2000b). Multiple goals, multiple pathways: The role of goal orientation in learning and achievement. Journal of Educational Psychology, 92, 544-555. doi:10.1037/0022-0663.92.3.544

Ponjuan, L., Conley, V. M., \& Trower, C. (2011). Career stage differences in pre-tenure track faculty perceptions of professional and personal relationships with colleagues. The Journal of Higher Education, 82, 319-346. doi: 10.1080/00221546.2011.11777204

Richardson, P. W., Karabenick, S. A., \& Watt, H. M. G. (2014). Teacher motivation: Theory and practice. New York, NY: Routledge.

Robbins, S. B., Lauver, K., Le, H., Davis, D., Langley, R., \& Carlstrom, A. (2004). Do psychosocial and study skill factors predict college outcomes? A meta-analysis. Psychological Bulletin, 130, 261-288. doi:10.1037/00332909.130.2.261

Scherer, K. R. (2005). What are emotions? And how can they be measured?. Social Science Information, 44, 695-729. doi:10.1177/0539018405058216

Schunk, D., Meece, J., \& Pintrich, P. (2013). Motivation in Education: Theory, research, and applications. Saddle River, NJ: Pearson.

Shin, J.C., \& Jung, J. (2014). Academics job satisfaction and job stress across countries in the changing academic environments. Higher Education, 67, 603-620. doi: 10.1007/s10734-013-9668-y

Statistisches Bundesamt (2019a). Bildung und Kultur. Personal an Hochschulen. Retrieved from: https://www.destatis.de/DE/Themen/Gesellschaft-Umwelt/Bildung-Forschung-Kultur/Hochschulen/Publikationen/Downloads-Hochschulen/personal-vorbericht5213402188004.pdf;jsessionid=67547A004C526F55E41BE6D0048CCF16.internet731?_blob=publicationFile

Statistisches Bundesamt (2019b). Bildung und Kultur. Studierende an Hochschulen. Vorbericht. Retrieved from: https://www.destatis.de/DE/Themen/Gesellschaft-Umwelt/Bildung-Forschung-Kultur/Hochschulen/Publikationen/Downloads-Hochschulen/studierende-hochschulen-vorb-2110410198004.pdf;jsessionid=67547A004C526F55E41BE6D0048CCF16.internet731?_blob=publicationFile

Statistisches Bundesamt (2019c). Lehrkräfte nach Schularten und Beschäftigungsumfang. Retrieved from: https://www.destatis.de/DE/Themen/Gesellschaft-Umwelt/Bildung-Forschung-Kultur/Schulen/Tabellen/allgemeinbildende-beruflicheschulen-lehrkraefte.html
Stupnisky, R. H., BrckaLorenz, A., \& Nelson Laid, T. F. (2019). How does faculty research motivation type relate to success? A test of self-determination theory. International Journal of Educational Research, 98, Advanced online publication. doi:10.1016/j.ijer.2019.08.007

Stupnisky, R. H. (2018, April). Motivation and emotions of university faculty: Predicting teaching and research performance, stress, and well-being. Symposium at the Motivation in Education Special Interest Group of the American Educational Research Association (AERA) Conference in New York, NY.

Stupnisky, R. H., BrckaLorenz, A., Yuhas, B., \& Guay, F. (2018). Faculty members' motivation for teaching and best practices: Testing a model based on self-determination theory across institution types. Contemporary Educational Psychology, 53, 15-26. doi:10.1016/j.cedpsych.2018.01.004

Stupnisky, R. H., Hall, N. C., Daniels, L. M., \& Mensah, E. (2017). Testing a model of pretenure faculty members' teaching and research success: Motivation as a mediator of balance, expectations, and collegiality. The Journal of Higher Education, 88, 376-400. doi:10.1080/00221546.2016.1272317

Stupnisky, R. H., Pekrun, R., \& Lichtenfeld, S. (2016). New faculty members' emotions: a mixed-method study. Studies in Higher Education, 41, 1167-1188. doi:10.1080/03075079.2014.968546

Stupnisky, R. H., Hall, N. C., \& Pekrun, R. (2019). The emotions of pretenure taculty: Implications for teaching and research success. The Review of Higher Education, 42, 1489-1526. doi:10.1353/rhe.2019.0073

Stupnisky, R. H., Weaver-Hightower, M. B., \& Kartoshkina, Y. (2015). Exploring and testing the predictors of new faculty success: A mixed methods study. Studies in Higher Education, 40, 368-390. doi:10.1080/03075079.2013.842220

Su, Y. L., \& Reeve, J. (2011). A meta-analysis of the effectiveness of intervention programs designed to support autonomy. Educational Psychology Review, 23, 159-188. doi:10.1007/s10648-010-9142-7

Sverdlik, A., Hall, N. C., McAlpine, L., \& Hubbard, K. (2018). The PhD experience: A review of the factors influencing doctoral students' completion, achievement, and well-being. International Journal of Doctoral Studies, 13, 361-388. doi:10.28945/4113

Tönjes, B., \& Dickhäuser, O. (2009). Längsschnittliche Effekte von Zielorientierungen auf Dimensionen des beruflichen Belastungserlebens im Lehrberuf. [Longitudinal effects of achievement goals on dimensions of professional stress experience in teaching.] Zeitschrift für Entwicklungspsychologie und pädagogische Psychologie, 41, 79-86. doi:10.1026/0049-8637.41.2.79

Thies, K., \& Kordts-Freudinger, R. (2019). German higher education academic staff's positive emotions through work domains. International Journal of Educational Research, 98. Advanced online publication. doi:10.1016/j.ijer.2019.08.004 
Umbach, P. D., \& Wawrzynski, M. R. (2005). Faculty do matter: The role of college faculty in student learning and engagement. Research in Higher Education, 46, 153184. doi:10.1007/s11162-004-1598-1

U.S. Department of Education (April 2019), National Center for Education Statistics, "State Nonfiscal Survey of Public Elementary/Secondary Education," 1981-82 through 2016-17; Private School Universe Survey (PSS), 198990 through 2015-16; National Teacher and Principal Survey (NTPS), 2015-16; Elementary and Secondary Teacher Projection Model, 1973 through 2028; and New Teacher Hires Projection Model, 1988 through 2028.

U.S. Department of Education (January 2018), National Center for Education Statistics, Integrated Postsecondary Education Data System (IPEDS), Spring 2016 and Spring 2017, Fall Enrollment component.

U.S. Department of Education (December 2017), National Center for Education Statistics, Higher Education General Information Survey (HEGIS), Human Resources component, Fall Staff section; IPEDS Spring 2014, Spring 2016, and Spring 2017.

Vansteenkiste, M., Lens, W., Elliot, A. J., Soenens, B., \& Mouratidis, A. (2014). Moving the achievement goal approach one step forward: Toward a systematic examination of the autonomous and controlled reasons underlying achievement goals. Educational Psychologist, 49, 153174. doi:10.1080/00461520.2014.928598.

Weinberg, B. A., Ownen-Smith, J., Rosen, R. J., Schwarz, L., Allen, B. M., Weiss, R. E., \& Lane, J. (2014). Science funding and short-term economic activity. Science, 344, 41-43. doi:10.1126/science. 1250055

Weiner, B. (1990). History of motivational research in education. Journal of Educational Psychology, 82, 616-622. doi:10.1037/0022-0663.82.4.616

Wild, E. (2012). Lehrmotivation im Kontext Hochschule Zusammenfassung der zweiten Paneldiskussion. [Teaching motivation in the context of higher education - Summary of the second panel discussion]. In F. G. Becker, G. Krücken, \& E. Wild, Von Anreizen, Kontextbedingungen und Reformen [About incentives, context conditions and reforms], (pp. 159-171). Bielefeld: W. Bertelsmann.

Wilkesmann, U., \& J. Schmid, C. (2014, May). Intrinsic and internalized modes of teaching motivation. Evidencebased HRM: A global forum for empirical scholarship, 2, 6-27. doi:10.1108/EBHRM-07-2013-0022

Winefield, T., Boyd, C., Saebel, J., \& Pignata, S. (2008). Update on national university stress study. Australian University Review, 50(1), 20-29.
Woolston, C. (2015). Graduate survey: Uncertain futures. Nature, 526, 597-600. doi:10.1038/nj7574-597a

Young, K. J., \& Kline, T. (1996). Perceived self-efficacy, outcome-efficacy and feedback: Their effects on professors' teaching development motivation. Revue canadienne des sciences du comportement/Canadian Journal of Behavioural Science, 28, 43-51. doi:10.1037/0008400x.28.1.43

Zhang, L. F., Fu, M., Li, D. T., \& He, Y. (2019). Emotions and teaching styles among academics: The mediating role of research and teaching efficacy. Educational Psychology, 39, 370-394. doi:10.1080/01443410.2018.1520970

Zhu, Y. Q., Gardner, D. G., \& Chen, H. G. (2018). Relationships between work team climate, individual motivation, and creativity. Journal of Management, 44, 2094-2115. doi:10.1177/0149206316638161

Note. This is a pre-copyedited, author-produced PDF of an article accepted for publication in International Journal of Educational Research following peer-review. This paper is not the copy of record and may not exactly replicate the final, authoritative version of the article. The final article is available via its DOI. 